\title{
REVIEW: AN EFFORTS TO INCREASE THE SOLUBILITY AND DISSOLUTION OF ACTIVE PHARMACEUTICAL INGREDIENTS
}

\section{IYAN SOPYAN ${ }^{1,4}$, DOLIH GOZALI ${ }^{1}$, SANDRA MEGANTARA ${ }^{2}$, RETNO WAHYUNINGRUM ${ }^{3}$, INSAN SUNAN KS ${ }^{1}$}

1Department of Pharmaceutical and Technology of Pharmacy, Faculty of Pharmacy, Universitas Padjadjaran, Bandung, Indonesia, 2Department of Pharmaceutical Analysis and Medicinal Chemsitry, Faculty of Pharmacy, Universitas Padjadjaran, Bandung, Indonesia, ${ }^{3}$ Department of Pharmacy, Faculty of Science and Technology, Universitas Sembilanbelas November, Kolaka, Indonesia, ${ }^{4}$ Study Center of Dosage Form Development, Faculty of Pharmacy, Universitas Padjadjaran, Bandung, Indonesia

Email: i.sopyan@unpad.ac.id

Received: 05 Jun 2021, Revised and Accepted: 16 Aug 2021

\section{ABSTRACT}

The most significant aspect of a drug's physicochemical nature is its solubility. If the medicine is in a dissolved form, it can dissolve and enter the membrane, resulting in a therapeutic effect. The pharmacokinetic phase of the drug in the body, which includes absorption, distribution, metabolism, and excretion, will be correlated with solubility. Some medications, however, have a low solubility. To obtain a therapeutic impact, an effort must be made to increase the drug's solubility. Based on the literature research, the goal of this paper is to explain approaches that can be utilized to improve solubility. In general, physical, chemical, and micelle formation efforts can all be used it to enhance solubility. Particle size reduction, crystal shape modification, and the utilization of matrices in the disperse phase are examples of physical alterations. pH adjustment, buffering, salt formation, complexation, and derivatization all are examples of chemical alterations. The employment of supercritical processes in solutions and also excipients such as surfactants, cosolvents, stabilizing solutions, and others are examples of how micelle formation can be modified.

Keywords: Solubility, Drug, Techniques increase solubility

(C) 2022 The Authors. Published by Innovare Academic Sciences Pvt Ltd. This is an open access article under the CC BY license (https://creativecommons.org/licenses/by/4.0/) DOI: https://dx.doi.org/10.22159/ijap.2022v14i1.43431. Journal homepage: https://innovareacademics.in/journals/index.php/ijap

\section{INTRODUCTION}

Solubility is the property in which a solid, liquid, or gas can dissolve in a solvent and form a homogeneous solution [1]. The degree of solubility is defined by how much solute is dissolved to a saturated state [2]. He equilibrium of the solution occurs when it is saturated because the reaction rate is constant. The units of solubility can be concentration, molality, mole fraction, mole ratio, and other units [3].

Table 1: Solubility criteria according to USP and BP

\begin{tabular}{ll}
\hline Description & Part of solvent required per part solute \\
\hline Very soluble & $<1$ \\
Freely soluble & $1-10$ \\
Soluble & $10-30$ \\
Sparingly Soluble & $30-100$ \\
slightly soluble & $100-1000$ \\
Very slightly soluble & $1000-10.000$ \\
Insoluble & $>10.000$ \\
\hline
\end{tabular}

Solubility is one of the common problems that are often encountered in the pharmaceutical field [4]. The solubility of the drug will correlate with the rate of absorption of the drug so that it is absorbed and produces a therapeutic effect [5]. N addition, solubility also determines the disposition of drugs in the body. Drugs with low solubility (lipophilic) will be bound to plasma proteins, distributed rapidly, and metabolized by the liver. Conversely, drugs with high solubility (hydrophilic) will be distributed in a limited manner and metabolized by the kidneys [6]. So it can be concluded that solubility plays an important role in the pharmacokinetic phase.

A drug can be defined to have a high solubility if it can be dissolved in $250 \mathrm{ml}$ of water media and has a $\mathrm{pH}$ of 1-6.8. Drugs that have low solubility are included in the BCS (Biopharmaceutic Classification System) class II and IV. The difference between the two lies in the level of permeability, where BCS class II has a high level of permeability. Therefore, drugs that are included in BCS class II only need to be modified in their solubility to achieve the desired therapeutic effect [7].

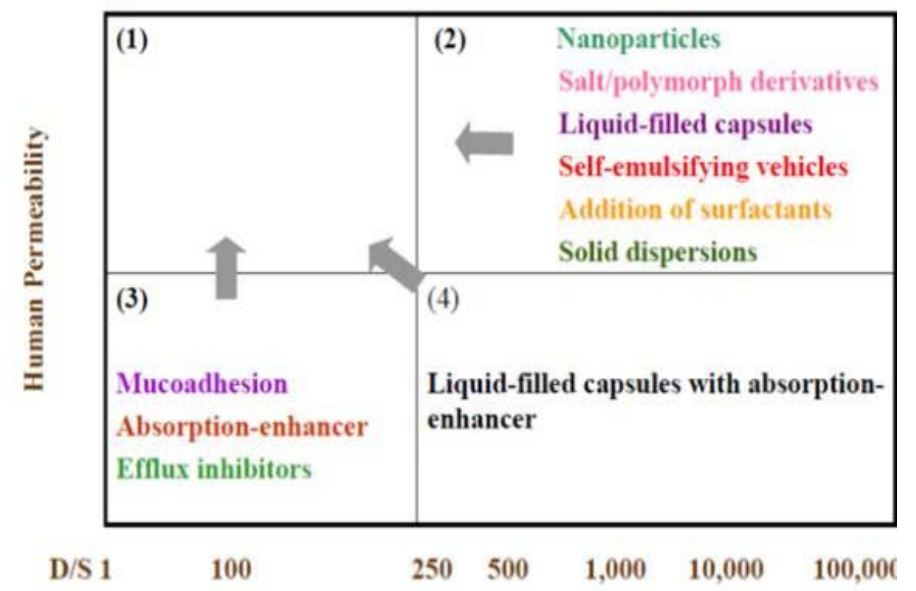

Fig. 1: Solubility enhancement technique according to BCS [7] 
This graph demonstrates some of the initiatives taken to increase the solubility and permeability of active medicinal ingredients. Nanoparticle creation, salt derivatization, solid dispersion formation, surfactant addition, emulsion, and soft capsule formation are all possible in BCS class II. Additional excipients, such as mucoadhesives, and enhanced absorption, can be added to class III BCS. It is feasible to add absorption-enhancing excipients and convert the formulation into soft capsules in addition to in-class IV BCS [8].

Solubility is affected by temperature, dielectric constant, $\mathrm{pH}$, solvent, particle size, polymorphism, salt form, pressure, and steric factor [9]. As a result, in recent years, techniques or procedures for enhancing solubility based on the aforementioned variables have been developed. This review will look at several studies that looked into different methods for increasing a drug's solubility.

\section{Methods}

The primary data source used is the internet using a search engine or search engines such as Google Scholar, NCBI, Springer, Science direct. Further searches are carried out manually based on the relevant bibliography so that other search sources are obtained, such as using trusted e-books or e-journals or those that have been accredited nationally and internationally.

\section{RESULTS AND DISCUSSION}

Techniques that are commonly used as an effort to increase solubility are carried out by the three methods as following [10]:

Table 3: Techniques for increasing solubility in physics, chemistry and micelle formation

\begin{tabular}{llc}
\hline Technique & Type of treatment & Reference \\
\hline Physical modification & Particle size reduction, crystal shape modification, use of carriers in disperse system. & Savjani et al., [10] \\
Chemical modification & Changes in pH, use of buffers, salt formation, complexation and derivatization. & Savjani et al., [10] \\
Micelle formation method & $\begin{array}{l}\text { Supercritical process in solution, the use of excipients such as surfactants, cosolvents, } \\
\text { stabilizing solutions, and others. }\end{array}$ & Savjani et al., [10] \\
\hline
\end{tabular}

Several other techniques used to increase the solubility of active pharmaceutical ingredients are also presented in the table below.

Table 4: Various techniques used in an effort to increase solubility

\begin{tabular}{ll}
\hline Method & Reference \\
\hline Formation of solid dispersions and complex molecules using beta-cyclodextrin as carrier & (Gupta, et al., 2016) [11] \\
Cocrystal formation between atorvastatin calcium and is nicotinamide and its characterization & (Gozali, et al., 2012), [12] \\
Increased solubility of ketoconazole with cocrystal formation & (Indra, et al., 2018) [13] \\
Formulation and evaluation in vitro eudagrite base nanosuspension & (Yadav, et al., 2012), [14] \\
Preparation of amorphous salt form of Na-furosemide to increase solubility and dissolution rate & (Nielsen, et al., 2013), [15] \\
Determination of the dissolution rate of a eutectic mixture of polyethylene glycol (PEG) and fenofibrate & (Law. et al., 2003) [16] \\
Effect of Bioavailability of Chitosan-Artovastati Conjugated Drugs Oral Preparations & (Anwar, et al., 2011) [17] \\
Preparation and Optimization of Self-Microemulsifying Drug delivery System (SMEDDS) dosage forms containing & (Lee et al., 2014) [18] \\
Fenofibrate & \\
\hline
\end{tabular}

\section{Complex formation}

By creating complex bonds with the carrier, complexation, also known as inclusion complex, is a way of enhancing the solubility of hydrophobic medicines. The existence of two combinations of molecules, typically drug compounds and transporters, causes complex formation. The medicine will create a strong relationship with the inside of the carrier, such as cyclodextrin, allowing it to dissolve along with the carrier. The size and shape of the drug component have a big impact on the binding that forms. One of the classifications of solid derivatives is the complexation technique [19].

Cyclodextrins are an example of a regularly used complexing agent. According to Hiremanth's (2006) research, the more betacyclodextrin used, the higher the solubility in water. The increase in solubility was due to the introduction of cyclodextrins in the drug structure, which created a hydrophilic cavity for water to occupy, breaking down into $\mathrm{H}+$ and $\mathrm{OH}$-particles and dissolving the active drug ingredient. The bonding of medicines with cyclodextrins is depicted in the image below.

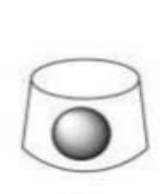

$\mathbf{I}$

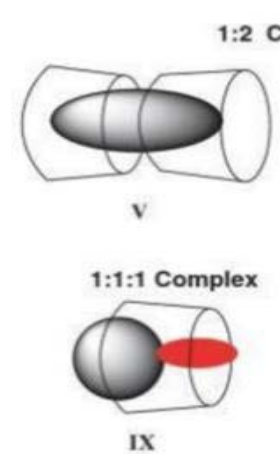

1:2 Complex

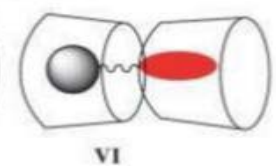

vI

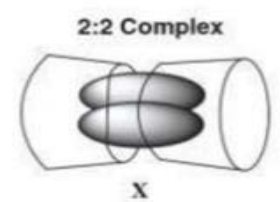

$\mathrm{x}$

1:1 Complex

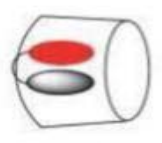

III

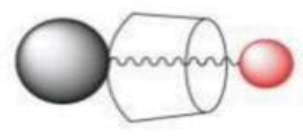

IV
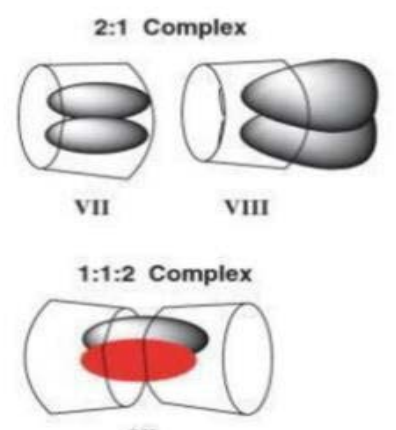

XI

Fig. 2: Types of inclusion complexes between the active drug substance and cyclodextrins [19] 
A water-soluble polymer may be involved in the bond between the cyclodextrin and the active medicinal component. The polymer will attach to the drug side-chain, increasing the volume of the cyclodextrin's matrix cavity [20].

Beta-cyclodextrin molecules have low water solubility. This is because the crystalline form of the molecule has a lower solubility than the amorphous form [21]. The size of the cyclodextrin cavity, as well as the thermodynamic interactions between cyclodextrins, active medicinal compounds, and solvents, can all affect the formation of inclusion complexes from cyclodextrins. The active medicinal ingredient's particle size and shape must be compatible with the cyclodextrin cavity. The stereochemistry and polarity of the active pharmacological component determine inclusion complex formation and molecular complexation [22].

\section{Solid dispersion}

A state of distribution of a drug molecule (whether amorphous, crystalline, or molecular) in which the molecule is surrounded by an inert chemical is known as a solid dispersion. This chemical is hydrophilic because it works as a carrier. There are several types of solid dispersion, including simple eutectic mixtures, glass solutions and derivatives, solid solutions, complexation, and the formation of amorphous precipitates with amorphous precipitate. The benefits of this solid dispersion include the capacity to lower drug particle size, convert the drug into an amorphous form to make it more soluble, increase drug wettability, and increase porosity [24]. Meanwhile, solid dispersion has the disadvantages of being unstable, absorbing water easily and therefore becoming moister, and the amorphous formation process being highly dependent on temperature and humidity. It is possible for medication molecules to crystallize and their solubility to decrease if the environment is not regulated during the manufacture and storage process [25].

Compounds that can be depressants include SSG (Sodium Starch Glycolate), PEG 6000, lactose, polymer poloxamer 407, eudragit E 100 , and others. The choice of dispersing compounds depends on the physicochemical properties of the active substance. The most important thing is that the dispersing compound must be inert to the active drug substance [24].

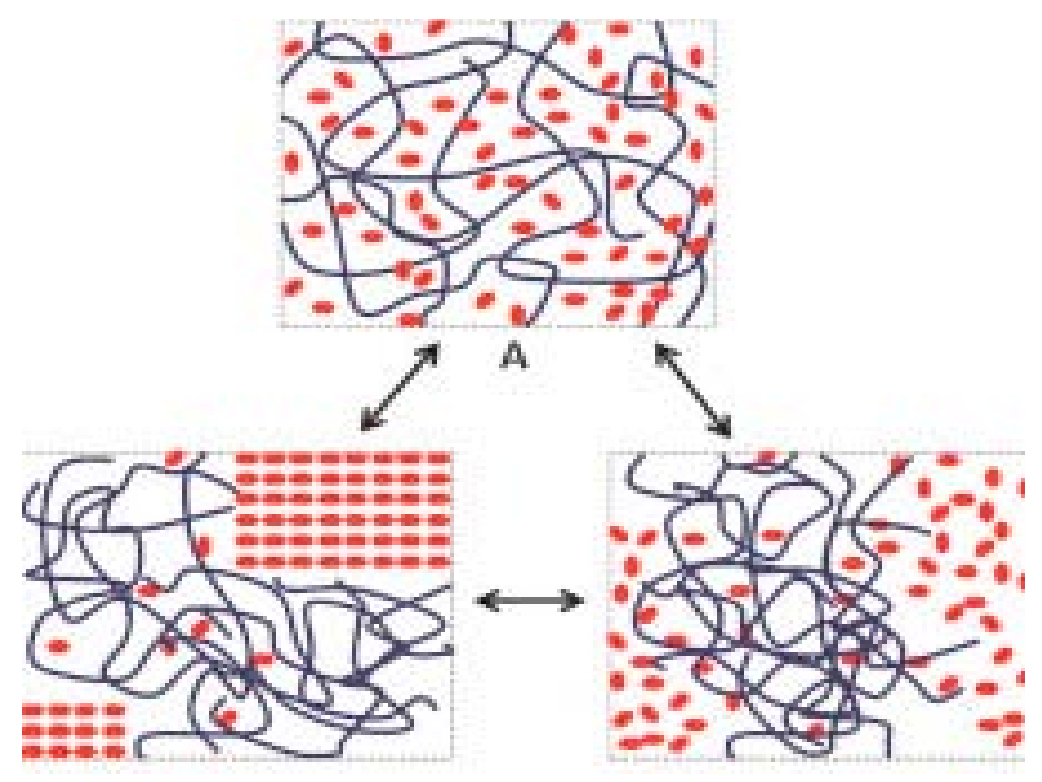

Fig. 3: Solid dispersion technic [24]

To make solid dispersions, the dissolving method, the melting method, a mixture of the two, or the melting dissolving method are all used. The active ingredient and carrier or dispersion are mixed in an organic solvent, the solution is evaporated, and the solid phase is crushed and sieved to ensure equal distribution. In the smelting process, the active ingredients and carrier's melting points are used. After the two have melted together, the mixture is rapidly cooled while stirring. After that, the solids are ground and sieved. The dissolving-melting method is a mixture of the previous method and the dissolving-melting method, in which the active component and carrier are dissolved in an organic solvent until melted, the solvent is evaporated, and the solid phase resulting is ground and sifted [26].

Characterization of solid dispersion can be done by Differential Scanning Calorimetry (DSC), X-ray diffraction, Scanning Electron Microscope (SEM) [27]. Since the solid dispersion system can change the crystalline form of the drug into an amorphous or partially crystalline form by forming a eutectic or monotectic, it is possible to characterize the solid dispersion results using this instrument [28].

\section{Cocrystalization}

One sort of modification in the alteration of the crystal habit is cocrystallization. Crystal habit can determine a molecule's stability, physicochemical qualities, and biological properties. As a result, solubility is related to crystal habit. The development of amorphous molecules is another sort of crystal habit alteration. Due to their physical instability, amorphous materials have a greater solubility than crystals, allowing for deformation when subjected to high energy [29].

Because it has the potential to improve physicochemical properties such as solubility, dissolution rate, bioavailability, and physicochemical stability of an active drug substance without affecting its pharmacological activity, the cocrystallization technique is one of the alternative approaches in the design of solid drug forms [29]. Crystal is a type of active substance polymorphism. Amorphous materials are less stable than crystals. However, the solubility of 80 percent of the active ingredient in the form of crystals is poor. To enhance solubility, crystals can be converted into cocrystals. Cocrystals are crystalline materials made up of two or more molecules arranged in the same lattice. A coformer, such as ascorbic acid, is required for the creation of cocrystals. Coformers will establish hydrogen bonds with the active ingredient to boost solubility. 


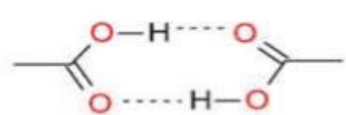

(1)

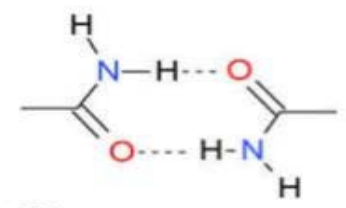

(3)
(2)

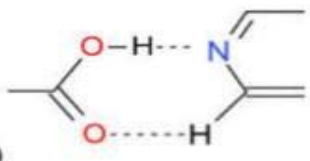

(4)

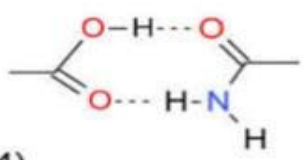

(5)

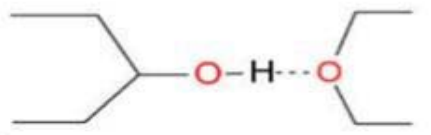

Fig. 4: Supramoleculer synthon of cocrystalization interaction [30]

Isonicotinamide and other coformers are used extensively in the cocrystallization process. Isonicotinamide and saccharin are two popular coformers used in the cocrystallization process. The bonds that form during the co-crystallization of simvastatin with saccharine coformers and atorvastatin with isonicotinamide are depicted in the diagram above [31, 32]. Solvent evaporation, slurry conversion, grinding, antisolvent addition, hot-melt extrusion, and supercritical fluid technology are some of the methods or procedures utilized to make cocrystals. Solvent evaporation and grinding, on the other hand, are often employed techniques [33].

Solvent evaporation is a cocrystal formation technique in which the active material and coformer are mixed in a solvent and then evaporated. Solid coformers are added to the active substance solution to convert it to a slurry. Stirring until a slurry forms to start the production of cocrystals in the process of adding coformer. The solvent is evaporated after the produced slurry has been allowed to stand for $48 \mathrm{~h}$ [33].

On the grinding method, there are two options: neat grinding (dry grinding) and liquid-assisted grinding (wet grinding). The only variation is whether or not solvents are used during the grinding process. Precipitation or recrystallization is achieved using the antisolvent addition method, which involves adding antisolvent to a solution of the active ingredient and coformer at room temperature with agitation. To employ the hot-melt extrusion method, you must first set the temperature. This approach can be used on a variety of active substances. And the last method, likely supercritical fluid technology, focuses more on the properties of the supercritical, antisolvent, solvent, and the process of increasing atomization so that the size and morphology of the cocrystals formed through this method can be adjusted [34]. Similar to the formation of solid dispersions, the result of the cocrystallization process is crystal molecules. Then the identification or characterization of the cocrystallization results can use the DSC, FTIR, x-ray diffraction, and PXRD instruments [35].

\section{Particle size reduction}

Solubility is closely related to particle size. The smaller the particle size, the greater the surface area so that the possibility of solvated particles is also greater. Decreasing the particle size to less than one micrometer is believed to increase the solvation pressure and cause interference with the solute interactions that facilitate the solubility process [36]. Nanosuspension technology has been developed at this time. Nanosuspension is a technique for increasing drug solubility in water under pressure by stabilizing crystalline micron particles. Precipitation, milling, and high-pressure homogenization are also performed on the crystal particles. Nanosuspension preparations have been demonstrated to improve solubility, absorption, bioavailability, AUC (Area Under Curve), and the time it takes for the medication to reach the maximum concentration in the body [37].

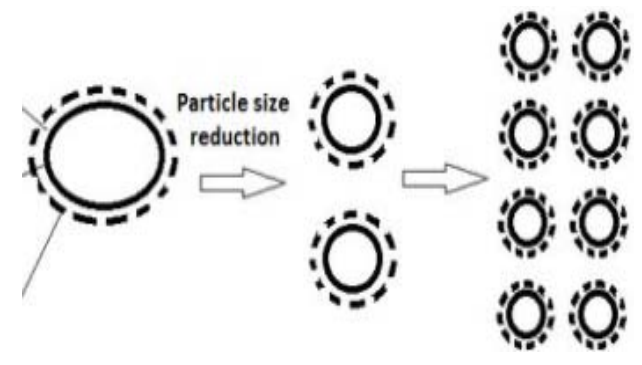

Fig. 5: Particle size reduction [37]

\section{Eutectic mixture}

The eutectic mixture technique is used on two molecules to lower the melting point of the mixture rather than the melting point of each molecule. The selected molecule is a molecule that does not interact and forms new chemical compounds, but at a certain ratio can inhibit the crystallization process from one another, thereby lowering the melting point. The increase in drug solubility is proportional to the decrease in the melting point [38].

One of the steps in the production of solid dispersions or crystallization is the eutectic mixture. Drug molecules are transformed to partially crystalline or amorphous in a moment of solid dispersion. As a result, it differs from a eutectic mixture, in which the crystalline phase remains intact after a procedure. The process of generating a eutectic is similar to the melting process of forming a solid dispersion, namely melting between two compounds and quick solidification. DSC, X-ray diffraction and SEM can be used to characterize the eutectic mixture's results. The x-ray diffraction pattern will reveal the mixed crystalline phase of two compounds [23].

\section{Derivatization}

By modifying or replacing a molecule's functional groups, solubility can be improved, resulting in a derivative or derivative molecule. When it comes to medications in the form of prodrugs, modifying or replacing the functional group when the drug enters the form is a common strategy to making the drug active. Conjugation synthesis processes that can be carried out in the form of prodrugs include acetylation, sulfatase, glucuronidation, and methylation. The purpose of this prodrug conjugation is to increase the drug's solubility in the body, resulting in higher bioavailability [17]. 


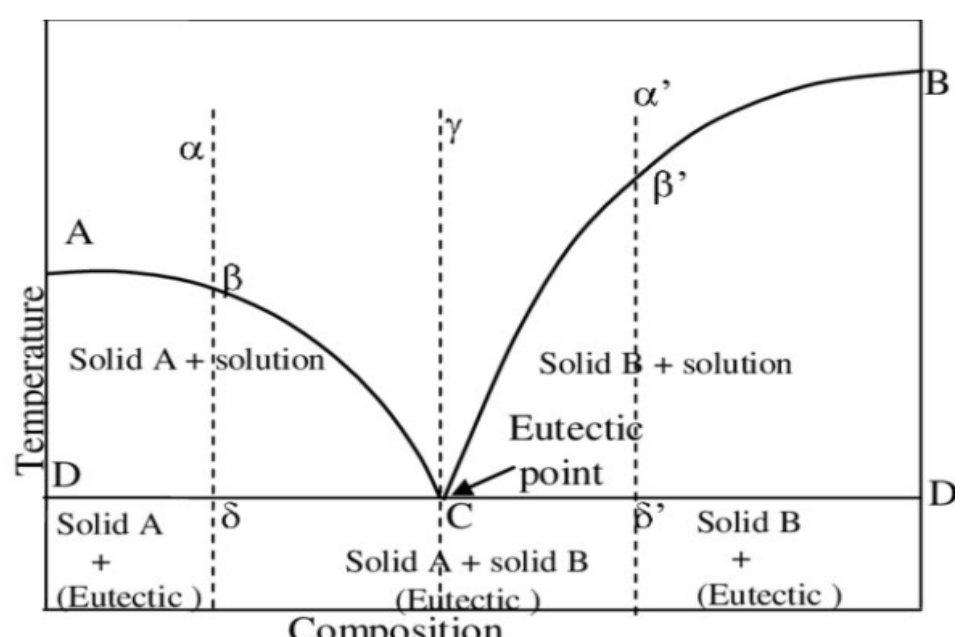

Composition

Fig. 6: Simple eutectic system [38]

Derivatization in operation is demonstrated by the artesunate compound. Artesunate is a semisynthetic derivative of artemisinin that is used to treat malaria. A kind of artesunate derivatization is hemisuccinate ester derivatization. Artesunate is often utilized as an antimalarial medicine in Southeast Asian patients who are resistant to standard antimalarials due to its greater water solubility compared to other artemisinin derivatives [39].

\section{Self-emulsifying drug delivery systems (SEDDS)}

SMEDDS (self-micro-emulsifying drug delivery system) and SMEDDS (self-nano emulsifying drug delivery system) are two forms of SEEDS formation processes (SNEDDS). Microemulsions and nanoemulsions are the only two varieties that differ in size. The goal of this method is to make medication molecules more soluble in oil. Oil molecules are made up of nano or micro-sized droplets that are coated with surfactants or co-surfactants to increase their solubility in the aqueous phase while also increasing and facilitating absorption in lipid membranes (such as the intestine). This method has been shown to have a higher solubility (about $87 \%$ for $30 \mathrm{~min}$ ) than powder dosage forms [18].

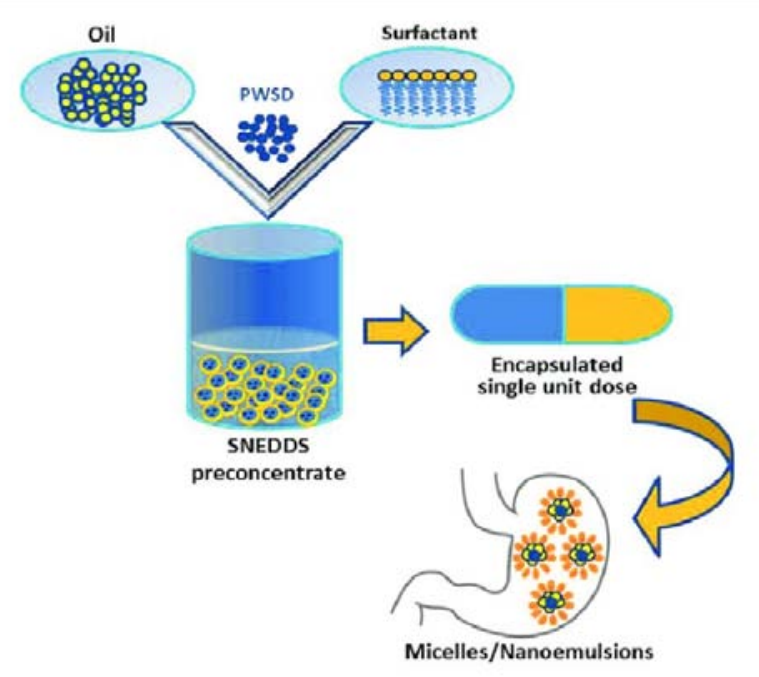

Fig. 7: The encapsulated SNEDDS designed for oral preparation [18]

Low drug stability and incompatibility, a restricted number of dose forms, and the possibility of precipitation during the storage method are all disadvantages of this SEDDS technology. As a result, to address the limitations of liquid SEEDS, the development of a solid SEDDS dosage form in the form of a powder is being considered. To make solid SEDDS, use the adsorption phenomenon, which includes utilizing a solid carrier that can adsorb the active medicinal ingredient. Glibenclamide compounds employing oleic acid as a fat basis and spironolactone compounds using the solid SEDDS technique have both proved the efficacy of the SEDDS technology. The pure compound has a higher solubility than the SEDDS method [40], as can be shown in these two cases.

\section{CONCLUSION}

A multitude of processes or approaches is employed to improve pharmaceutical solubility. Solubility enhancement techniques include physics, chemistry, and micellar creation. Every strategy has advantages and disadvantages, and the type of drug molecule determines how it is used. Drug solubility is important because it impacts the pharmacokinetics and pharmacodynamics of medications in the body.

\section{ACKNOWLEDGEMENT}

All authors would like to thank the Ministry of education of the republic of Indonesia and DRPMI Universitas Padjadjaran for all support.

\section{AUTHORS CONTRIBUTIONS}

All authors have contributed equally.

\section{CONFLICT OF INTERESTS}

Declared none

\section{REFERENCES}

1. Lachman L, Lieberman H, Kanig JL. Teori dan praktek Farmasi Industri II (Edisi 3). Terjemahan Siti Suyatmi, Jakarta. UI Press: 2008. p. 110-2.

2. Gong Y, Grant DJW, Britain HG. Principles of solubility. In: New York: Springer; 2007.

3. Aulton ME, Taylor K. Aulton's pharmaceutics: the design and manufacture of medicines. Elsevier Health Sciences; 2013. p. 302-5.

4. Van den Mooter G. The use of amorphous solid dispersions: A formulation strategy to overcome poor solubility and dissolution rate. Drug Discov Today Technol. 2012;9(2):e7985. doi: 10.1016/j.ddtec.2011.10.002.

5. Al-Hamidi H, Edwards AA, Mohammad MA, Nokhodchi A. To enhance the dissolution rate of poorly water-soluble drugs: glucosamine hydrochloride as a potential carrier in solid dispersion formulations. Colloids Surf B Biointerfaces. 2010;76(1):170-8. doi: 10.1016/j.colsurfb.2009.10.030, PMID 19945828. 
6. Alavijeh MS, Chishty M, Qaiser MZ, Palmer AM. Drug metabolism and pharmacokinetics, the blood-brain barrier, and central nervous system drug discovery. Neurorx. 2005;2(4):554-71. doi: 10.1602/neurorx.2.4.554, PMID 16489365.

7. Mehta M. Biopharmaceutics classification system (bcs). United Kingdom: John Wiley and Sons; 2017. p. 213.

8. Jaiswal SB, Shamsuddin SSS, Shehzad SS, Brahmankar DM. Pelletization in rotary shaker effect of equipment variables on pelletization of ferrous fumarate. Drug Dev Ind Pharm. 1995;21(18):2109-20. doi: 10.3109/03639049509065894.

9. Babu NJ, Nangia A. Solubility advantage of amorphous drugs and pharmaceutical cocrystals. Cryst Growth Des. 2011;11(7):2662-79. doi: 10.1021/cg200492w.

10. Savjani KT, Gajjar AK, Savjani JK. Drug solubility: importance and enhancement techniques. ISRN Pharm. 2012;2012:195727. doi: 10.5402/2012/195727, PMID 22830056.

11. Gupta S, Sawarkar S, Ravikumar P. Solubility enhancement of poorly water-soluble protease inhibitor. Int J Pharm Sci Res. 2016;7:252-8

12. Gozali D, Bahti HH, Soewandhi SN, Abdassah M. Pembentukan Kokristal antara kalsium atorvastatin dengan Isonikotinamid dan Karakterisasinya. Abstrak; 2012. Available from: http://repository.unpad.ac.id/23689.

13. Indra I, Janah FM, Aryani R. Enhancing the solubility of ketoconazole via pharmaceutical cocrystal. J Phys.: Conf Ser. 2019;1179(1):012134. doi: 10.1088/1742-6596/1179/1/ 012134.

14. Yadava SK, Naik JB, Patil JS, Mokale VJ, Singh R. Enhanced solubility and bioavailability of lovastatin using stabilized form of self-emulsifying drug delivery system. Colloids and Surfaces A: Physicochemical and Engineering Aspects. 2015;481:63-71. doi: 10.1016/j.colsurfa.2015.04.026.

15. Nielsen LH, Gordon S, Holm R, Selen A, Rades T, Müllertz A. Preparation of an amorphous sodium furosemide salt improves solubility and dissolution rate and leads to a faster Tmax after oral dosing to rats. Eur J Pharm Biopharm. 2013;85(3 Pt B):942-51. doi: 10.1016/j.ejpb.2013.09.002, PMID 24075980.

16. Law D, Wang W, Schmitt EA, Qiu Y, Krill SL, Fort JJ. Properties of rapidly dissolving eutectic mixtures of poly (ethylene glycol) and fenofibrate: the eutectic microstructure. J Pharm Sci. 2003;92(3):505-15. doi: 10.1002/jps.10324, PMID 12587112.

17. Anwar M, Warsi MH, Mallick N, Akhter S, Gahoi S, Jain GK, Talegaonkar S, Ahmad FJ, Khar RK. Enhanced bioavailability of nano-sized chitosan-atorvastatin conjugate after oral administration to rats. Eur J Pharm Sci. 2011;44(3):241-9. doi: 10.1016/j.ejps.2011.08.001, PMID 21864678.

18. Lee EH. A practical guide to pharmaceutical polymorph screening and selection. Asian J Pharm Sci. 2014;9(4):163-75. doi: 10.1016/j.ajps.2014.05.002.

19. Bekers O, Uijtendaal EV, Beijnen JH, Bult A, Underberg WJM. Cyclodextrins in the pharmaceutical field. Drug Dev Ind Pharm. 1991;17(11):1503-49. doi: 10.3109/03639049109026630.

20. Valero M, Tejedor J, Rodriguez LJ. Encapsulation of nabumetone by means of-drug: ( $\beta$-cyclodextrin) 2 : Polyvinylpyrrolidone ternary complex formation. J Lumin. 2007;126(2):297-302. doi: 10.1016/j.jlumin.2006.07.028.

21. Salustio PJ, Feio G, Figueirinhas JL, Pinto JF, Cabral Marques HM. The influence of the preparation methods on the inclusion of model drugs in a $\beta$-cyclodextrin cavity. Eur J Pharm Biopharm. 2009;71(2):377-86. doi: 10.1016/j.ejpb.2008. 09.027, PMID 18977436.
22. Tong WQT, Wen H. Applications of complexation in the formulation of insoluble compounds. In: Water-insoluble drug formulation. CRC Press; 2008. p. 147-74.

23. Kumar P, Singh C. A study on solubility enhancement methods for poorly water-soluble drugs. Am J Pharmacol Sci. 2013;1(4):67-73. doi: 10.12691/ajps-1-4-5.

24. Huang Y, Dai WG. Fundamental aspects of solid dispersion technology for poorly soluble drugs. Acta Pharm Sin B. 2014;4(1):18-25. doi: 10.1016/j.apsb.2013.11.001, PMID 26579360.

25. Sridhar I, Doshi A, Joshi B, Wankhede V, Doshi J. Solid dispersions: an approach to enhance the solubility of poorly water-soluble drug. J Sci Innov Res. 2013;2:685-94.

26. Fudholi A. Disolusi dan pelepasan obat in vitro. Pustaka Pelajar Yogyakatra. 2013. p. 115

27. Martin AM, Swarbrick J, Cammarata A, Farmasi Fisik, Terjemahan Yoshita. Jakarta: UI Press; 1990. p. 203-4.

28. Craig DQ. The mechanisms of drug release from solid dispersions in water-soluble polymers. Int J Pharm. 2002;231(2):131-44. doi: 10.1016/s0378-5173(01)00891-2, PMID 11755266.

29. Alonzo DE, Zhang GG, Zhou D, Gao Y, Taylor LS. Understanding the behavior of amorphous pharmaceutical systems during dissolution. Pharm Res. 2010;27(4):608-18. doi: 10.1007/s11095-009-0021-1, PMID 20151181.

30. Aakeröy CB, Salmon DJ. Building co-crystals with molecular sense and supramolecular sensibility. Cryst Eng Comm. 2005;7(72):439-48. doi: 10.1039/b505883j.

31. Sopyan I, Sari IM, K IS. Solid-state characterization of a novel physical interaction (paracetamol-chlorpheniramine maleate). Int J App Pharm 2018;10(1). doi: 10.22159/ijap.2018v10i1.22840.

32. Hairunnisa H, Sopyan I, Gozali D. Ko-kristal: nikotinamid sebagai koformer. JFB. 2019;10(2):113-22. doi: 10.52434/jfb.v10i2.652.

33. Sopyan I, Syah ISK, Nurhayti D, Budiman A. Improvement of simvastatin dissolution rate using derivative non-covaalent approach by solvent drop grinding method. Int J Appl Pharm. 2020;12:21-4.

34. Liu R, Drug WI. Formulation. 2nd ed. Vol. 686. CRC Press; 2008. p. 235.

35. Lin HL, Hsu PC, Lin SY. Theophylline-citric acid co-crystals are easily induced by DSC-FTIR microspectroscopy or different storage conditions. Asian J Pharm Sci. 2013;8(1):19-27. doi: 10.1016/j.ajps.2013.07.003.

36. Junghanns JU, Muller RH. Nanocrystal technology, drug delivery and clinical applications. Int $\mathrm{J}$ Nanomedicine. 2008;3(3):295-309. doi: 10.2147/ijn.s595, PMID 18990939.

37. Yadav SK, Mishra S, Mishra B. Eudragit-based nanosuspension of poorly water-soluble drug: formulation and in vitro-in vivo evaluation. AAPS PharmSciTech. 2012;13(4):1031-44. doi: 10.1208/s12249-012-9833-0, PMID 22893314.

38. Stott PW, Williams AC, Barry BW. Transdermal delivery from eutectic systems: enhanced permeation of a model drug, ibuprofen. J Control Release. 1998;50(1-3):297-308. doi: 10.1016/s0168-3659(97)00153-3, PMID 9685897.

39. Gaudin K, Langlois MH, Barbaud A, Boyer C, Millet P, Fawaz F, Dubost JP. Stability of artesunate in pharmaceutical solvents. J Pharm Biomed Anal. 2007;43(3):1019-24. doi: 10.1016/ j.jpba.2006.09.039, PMID 17084575.

40. Sharma S, Khinch MP, Sharma N, Agrawal D, Gupta MK. Approches to development of solid-self micron emulsifying drug delivery system: formulation technices and dosage forma review. Asian J Pharm Res Dev. 2013;1:146-56. 